\title{
The fall and rise of general practice
}

\author{
Ronald Gibson
}

One choice open to the newly qualified doctor of the 1940 s was to go into general practice. He required no special training or higher degree and found a practice by answering advertisements in the medical press, by following up recommendations from a colleague, or, if he found an area that he particularly favoured, by taking a risk and just "squatting." He tended to prefer to practise near his medical school.

The choice of general practice as a career was remarkable because general practitioners were known to housemen in teaching hospitals only as voices on the telephone. They were rarely, if ever, seen in the hospital, and their daily routine and responsibilities were a mystery. The choice of general practice as a career was motivated either by lack of finance or a genuine and unquenchable wish to be responsible for the total care of the whole patient from the cradle to the grave. Those young doctors left the comfort and security of their teaching hospital for the loneliness and intellectual isolation (Mr Bevan's words) of general practice.

Practices varied from single handed to groups of seven or more and from wholly private to wholly "panel" (National Health Insurance), or a mixture of both. The panel was organised in 1912 to meet the needs of those earning a small wage. It made no provision for their dependants and did not provide any form of hospital or specialist treatment.

Some general practitioners could supplement the practice income by part time work in hospital or occupational health; as police surgeons, school doctors, or prison doctors; or in the armed forces reserve or on medical boards.

The workload did not depend entirely on the size of the practice. Some patients gave far more trouble and expected more from their doctors than others. Unnecessary calls were more likely to come from the private sector, and private patients expected to be given more time than their "panel" equivalents. Distances to be travelled affected the workload, as did the number of elderly people in the practice and the hours devoted to other appointments.

\section{Life as a general practitioner}

My experience of practice in the denser conurbations was limited to my days on the district at Barts. I became part of a two man practice and bought a 5/12th share by means of a one and a half year purchase. This brought me in $£ 700$ a year. After a month's trial (my only vocational training) I took up residence with my wife and baby about half a mile from my partner. He and I rarely met except when we passed each other in our cars. With some pride I put up a plate.

There was no special accommodation for patients and no physical separation of private from panel. Two ground floor rooms were used for waiting and consulting. My wife or a maid opened the front door. Not far away was a seven man practice, most of the members of which had hospital appointments. This, I am sure, mirrored general practice at its best in those days. It certainly highlighted the difference between the haves and the have nots: those with work in the hospital and those without. I am told that competition was pretty tough, but this did not affect me-I was too small to be a danger to anyone. I received a quarterly cheque from the practice and I still have vivid memories of my wife and me sitting around a table and sending off bills to "private" patients. We knew that most of these would never be paid.

The doctor's garb in those days was a sombre suit with waistcoat and tie. (I well remember the reaction of an emeritus professor of medicine to a professional visit from a young doctor dressed in shirt sleeves. He refused to believe me that in spite of appearances this young man was an excellent doctor.) I was instructed to visit every doctor in the neighbourhood and to leave my card. These visits were duly returned. Today such an exercise would take months. There were strict rules of etiquette to guide the young doctor in his professional life. One of these concerned the ritual of the consultation with a colleague in the patient's home. Sadly this tradition has been discarded and too often today's consultant is left to visit alone.

\section{Little except patience and sympathy}

In my area there was little abject poverty, surgery sessions were, in the main, polite, and patients were clean and well dressed. Night calls came via the front door (there were few telephones) and were delivered by a neighbour or a rather frightened small boy, either of whom could be used as a guide on the return journey. Even in this part of the country some streets were not pleasant to visit at night and the small boy had to be pressed into service to guard the car.

Often there was little that could be done for the patient. Much depended on the doctor's personality to

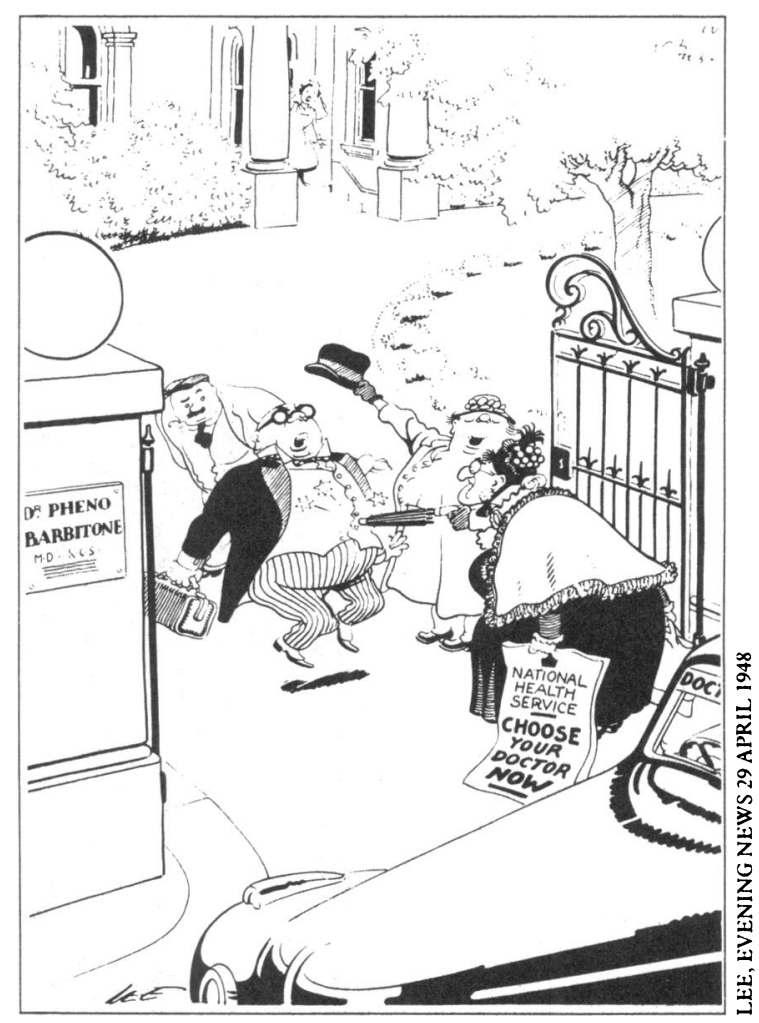

Winchester, Hampshire SO23 9HJ

Sir Ronald Gibson, DM
BMJ VOLUME 297

2 JULY 1988 
calm and reassure with patience, sympathy, and understanding - all of which took more time than scribbling a prescription and leaving. A case of acute bronchitis or pneumonia could require three visits a day in 1940. Now it needs a single visit, capsules on the bedside table, and "let me know how you are in a couple of days." This is good for the doctor's workload but almost lethal to the doctor-patient relationship.

Yet I wonder if the life of this part-doctor, partpriest, and part-social worker was very different in those days before the NHS. There were district nurses, midwives, and health visitors. They were employed by the local authorities and worked from separate buildings looking after patients from all the practices. They were excellent at their jobs, but their separation from each other exaggerated the general practitioner's sense of isolation, and patients in the community lacked the advantages of the team care available in hospital. It struck me that care would be more effective if all those responsible worked from the same building and looked after the same patients. It was many years before this ideal was realised.

\section{Plus ça change}

In February 1940 I wrote a paper on "my first year in general practice." One quotation is worth including here: "The doctor is made use of in small proportion in his capacity as a medical man as compared with his ability to adjudicate in family quarrels; to lead little Tommy back on to the straight and narrow path; to discuss the capabilities and potentialities of the new domestic; to certify as unfit for employment an elderly patient in his eighties who anyone but those with whom he is insured could see was not only incapable of work but also of every living function other than the effort of obtaining a certificate from the doctor; to issue countless times a day 'a tonic please doctor'; to have at one's fingertips all the ins and outs of the relationship between the patient and his insurance company; to write letters to employers to answer questions on the progress of the employee; to interview the friends and relatives of the sick and the deceased." The reader may not think this workload very different from today's.

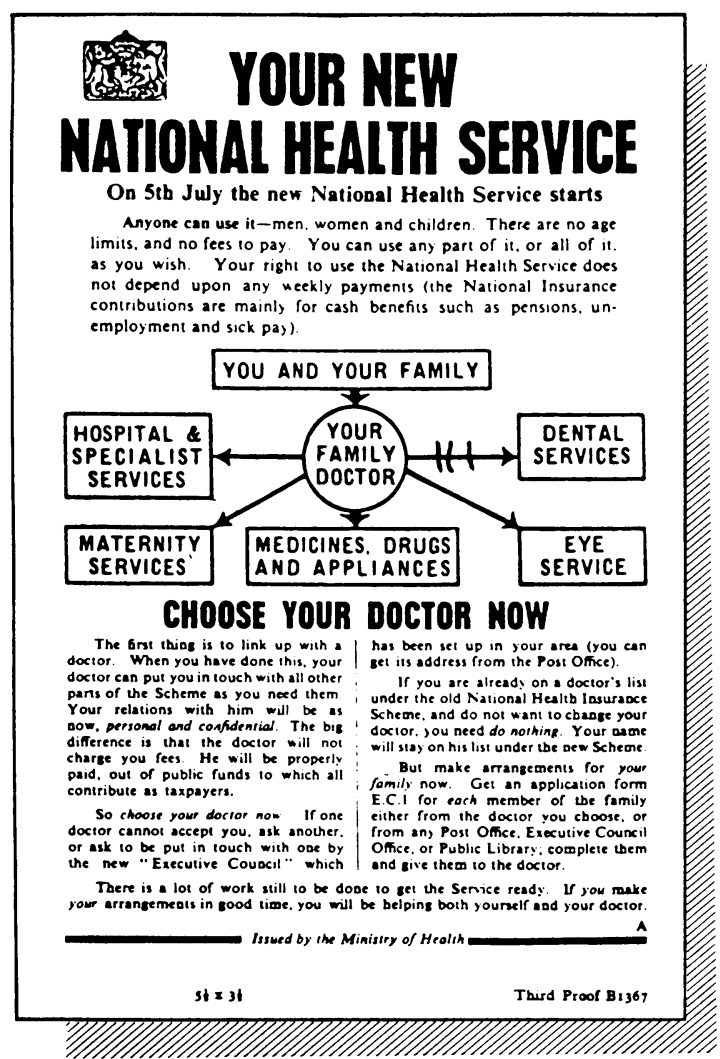

A few weeks after writing this I joined the armed forces and was posted abroad. At home things were taking shape towards the establishment of a comprehensive health service which would provide a complete general practice and hospital service and expand the preventive, social, and environmental services provided by local authorities. There were debates, arguments, and negotiations and then came the appointed day. A state salaried service had been avoided, and general practitioners were independent contractors with Executive Councils.

On my return from war service my partner agreed to do surgeries in my house, thus creating the semblance of a central surgery. We employed a secretary cum receptionist and converted the pantry into a treatment room cum office. The health service entitled the whole population to register with a general practitioner. We had no idea of the eventual size of the practice or of the number who would decide to remain as private patients. It was soon obvious that bad debts had been virtually eliminated but in their place was an ominous workload that it might be impossible to meet. The nation set out to enjoy a non-stop party with the general practitioners doling out the free gifts.

Nevertheless, there was a good deal of real need appearing in the surgeries that could not be met before because of financial restrictions. This applied particularly to housewives and mothers, who had been sacrificing their own health and giving precedence to their husbands and children. Conditions that had been unrecognised or ignored by patients now appeared in the surgery and could be dealt with free of charge. Many patients had to be referred to hospital for specialist opinions and treatment. Innumerable certificates, notably for eye examinations, were presented for signature. The items for which the general practitioner was now held responsible seemed endless. There had been no time to prepare the public for the act, no health education, and no adequate explanation. General practitioners were left to bear the brunt.

In case I seem to be exaggerating let me give an example. One night the duty doctor received four calls. The first because a doctor on duty might have some petrol available; another to a retired nurse who could not sleep, did not want to wake a doctor son downstairs, and wondered if the doctor on duty could call with a sleeping tablet; a third to a patient who called two doctors to make sure that one turned up; and a fourth that was genuine. The nadir in general practice was not far off.

\section{General practice at a low ebb}

Meanwhile, we had leased a house for use as a central surgery and taken on an "assistant with a view." We had tried to eliminate the queue of waiting patients down the passage (sometimes into the street) by instituting an appointment system. All improvements in those days were at the doctor's own expense. The better the standard of accommodation and equipment the less was left for the general practitioner. We did our best to examine every patient and we revelled in open access to the radiography and laboratory services and domiciliary visits by consultant colleagues.

To meet the demand standards in general practice started to slip. Repeat prescriptions were issued at the request of receptionists without the patient being seen by the doctor; drugs-including hypnotics and tranquillisers-were given out in large quantities with too many items on one script; certificates were issued with the patient unseen by the doctor; and deputies were employed beyond the limits suggested. Worst of all, receptionists seemed like "dragons" to patients trying in vain to see the doctor with whom they were registered. Those in genuine need could find it difficult to arrange an early appointment. 


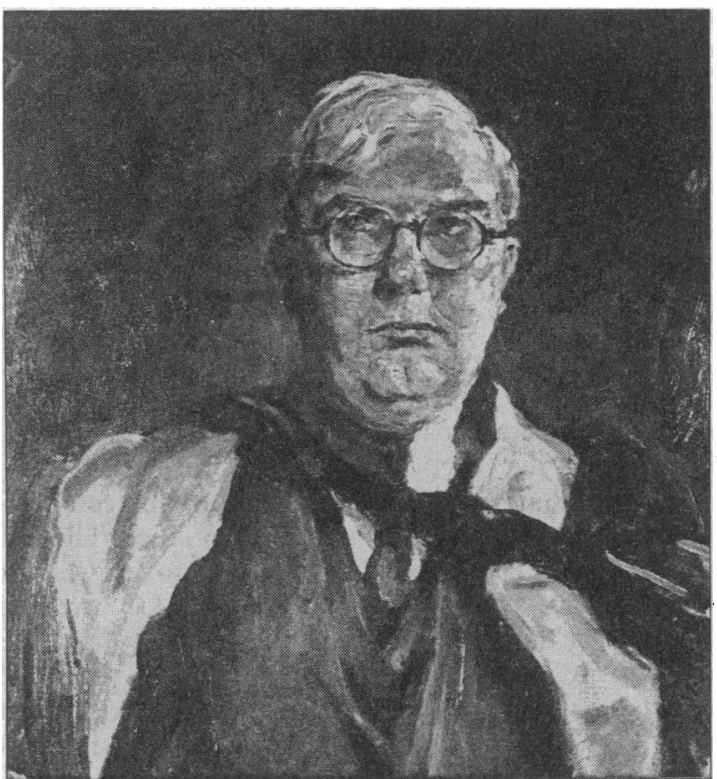

General practice reached its lowest ebb. The nation had overdone the advantage it was taking of a group of vocationally dedicated men and women. This most valuable and vital service was being abused to its death Something had to be done.

Some excellent reports had been written recognising and exposing the need and making recommendations. Eventually, all these were overtaken by the production of a Charter of General Practice, which analysed the general practitioners' service under the National Health Service Act and found acceptable answers to most of the defects it exposed (with the exception of the level of remuneration, which was to come later). In particular, it reversed the direction of the act so that good practice was recognised, encouraged, and rewarded. It brought together all the constructive efforts that had been developing over the years and was designed to produce a better family doctor service for the people.

General practitioners already had their own royal college and the opportunity of achieving membership through an examination. Vocational training was now to be recognised in the statutes and no longer practised by voluntary arrangements between some partnerships and eager trainees. Group practices were encouraged with all the caring professions working together in the same premises on the same group of patients. The employment of managers, secretaries, receptionists, and appointment clerks was recognised. General practitioners were to be accepted in hospitals as clinical assistants and in general practice as vocational trainers. Postgraduate medical centres were built in the hospitals. These contained libraries, lecture theatres, and refectories where doctors of all disciplines could meet, talk, debate, and learn together. In some group practice common rooms a similar exercise is now in vogue. Collaboration here between the general practitioners and their specialist colleagues is of invaluable help to the patient. It is also a worthwhile form of postgraduate education for the general practitioner and enables the specialist to see his patient at the level of primary care.

General practice has come a long way since the days of the lonely, untrained medical graduate finding his own way round a mysterious discipline. His professional life is now as rewarding as any, and he is no longer an office boy, a sieve, or one who (according to Lord Moran's description) has fallen off the hospital ladder. Patient demand will always exist, but it must be maintained at an acceptable level so that sufficient time is available to give adequate care to those in genuine need.

In the 1930s death was a likely sequel of illness more often than today. There was an awareness of the limited armoury available to the general practitioner in his fight against disease and consequently a greater appreciation of his efforts. He was accepted as a rather special member of the community-a veritable demigod. This image has changed for two reasons. Many patients today have never known anything but a comprehensive health service, apparently free to all. It is accepted by the majority with little concern for its value to them or its total cost. The general practitioner is the principal agent of this service and the patient's first contact with it. Secondly, the radio, television, and the press have intruded into doctors' professional lives. Any subject remotely associated with medicine is a winner and little seems sacred any longer. The days of working in privileged isolation are over.

Nevertheless, most new entrants to general practice today are no different from those who qualified in the 1930s. They have come to terms with the changing face of their discipline. Their vocation has been acknowledged and encouraged through vocational training and the opportunity to become members of a fully integrated primary health care team. Their contribution to the health and welfare of the community is of greater value today because the health service is now clearly seen to be founded on the service they are able to give. General practice is alive and well, but there is much still to be done and the next 40 years will be interesting to watch.

\title{
Doctor-patient relationships-as close as ever
}

\author{
Walter Hedgcock
}

In 1948 we were still adjusting back to Civvy Street, to peculiarities such as rationing and Nye Bevan. Since 1934 I had been in partnership in a middle class practice caring for people from all stations of life in the town and surrounding countryside. A "free for all" National Health Service in general practice seemed surprising and needless.

Most of our patients paid reasonable graded private price club scheme which was specially tailored for them. There was also a tiny confidential free list of elderly infirm people who had fallen on hard times: they were never charged. One of these, fortuitously in my area, had an obliging poacher as a dependant.

No one was ever refused attention, bad debts were virtually unknown, and I cannot remember excessive demands being made. Our relationship with all our patients was one of mutual respect, goodwill, and friendliness. However, it was rumoured that all was 